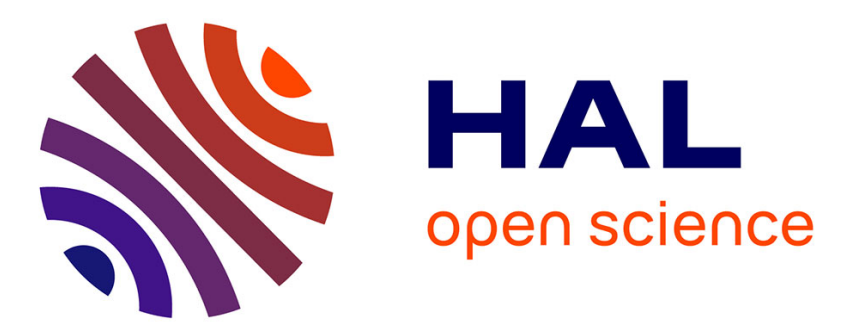

\title{
Signal recognition particle (SRP) positive myositis in a patient with cryptogenic organizing pneumonia (COP)
} Felix Wantke, Meinhard Kneussl, Marianne Hubner, Kurt Derfler, Thomas Brücke, Sabine Schmaldienst

\section{- To cite this version:}

Felix Wantke, Meinhard Kneussl, Marianne Hubner, Kurt Derfler, Thomas Brücke, et al.. Signal recognition particle (SRP) positive myositis in a patient with cryptogenic organizing pneumonia (COP). Rheumatology International, 2009, 30 (10), pp.1361-1365. 10.1007/s00296-009-1059-4 . hal00552490

\section{HAL Id: hal-00552490 \\ https://hal.science/hal-00552490}

Submitted on 6 Jan 2011

HAL is a multi-disciplinary open access archive for the deposit and dissemination of scientific research documents, whether they are published or not. The documents may come from teaching and research institutions in France or abroad, or from public or private research centers.
L'archive ouverte pluridisciplinaire HAL, est destinée au dépôt et à la diffusion de documents scientifiques de niveau recherche, publiés ou non, émanant des établissements d'enseignement et de recherche français ou étrangers, des laboratoires publics ou privés. 


\title{
Signal recognition particle (SRP) positive myositis in a patient with cryptogenic organizing pneumonia (COP)
}

\author{
Felix Wantke • Meinhard Kneussl • Marianne Hubner • \\ Kurt Derfler · Thomas Brücke · Sabine Schmaldienst
}

Received: 19 May 2009 / Accepted: 28 June 2009 / Published online: 29 July 2009

(C) Springer-Verlag 2009

\begin{abstract}
We report of a 46-year-old female patient with cryptogen organizing pneumonia preceeding the rare SRP positive necrotising myositis without cardiac involvement and no sign of dysphagia. Myositis showed full regression without oral immune suppression but with extracorporeal treatment, performed as a combined therapy of plasmaexchange and immunoadsorption. After 33-month of treatment, anti-SRP antibodies were not detectable any more.
\end{abstract}

Keywords Autoimmune myositis $\cdot$ Signal recognition particle $\cdot$ Cryptogen organizing pneumonia .

Plasmaexchange $\cdot$ Immunoadsorption

\section{Introduction}

A 46-year-old female patient presented with progressive dyspnoea in January 2005. Lung function testing revealed a FEV1 of $1.961(61 \%)$, a vital capacity of 2.821 (72\%), FEV1/VC of $69 \%$, and a diffusion capacity of $82 \%$ calculated to the alveolar volume. The chest X-ray revealed diffuse bilateral opacities of the lower lobes, a high resolution CT scan showed diffuse ground glass opacity of the left

F. Wantke $(\bowtie) \cdot$ M. Kneussl $\cdot$ M. Hubner

Department of Pneumonology, Medical University of Vienna,

Wilhelminenspital, Vienna, Austria

e-mail: felix.wantke@wienkav.at

K. Derfler $\cdot$ S. Schmaldienst

Division of Nephrology and Dialysis,

Medical University of Vienna, Vienna, Austria

T. Brücke

Department of Neurology, Medical University of Vienna,

Wilhelminenspital, Vienna, Austria upper and lower lobe as well as the middle lobe. Chemically a normal differential blood count and a normal total $\operatorname{IgE}(43 \mathrm{kU} / \mathrm{l})$ were found. ASLT was marginally elevated and antinuclear antibodies against signal recognition particle (anti-SRP; titer $>1: 80$ ) were found. Arterial blood gas analysis at rest was normal whereas at exertion $(50 \mathrm{~W}$ for $5 \mathrm{~min}) \mathrm{pO} 2$ declined to $64 \mathrm{mmHg}$ and $\mathrm{pCO} 2$ was unchanged.

Due to dyspnoea, the patient was investigated in another hospital in December 2004. Bronchoscopy was done and broncheoalveolar lavage revealed a reduced CD4/CD8 ratio, a lymphocytosis of $37 \%$ and activated $\mathrm{T}$ cells. In the histology alveolitis with lymphocytes, plasma cells, histiocytes, sparse eosinophils but no granulomas were found. The patients manson repeatedly suffered from water damage and mold growths on the walls of her indoor pool. Indoor air sampling was done, but mold exposure was in the low to moderate range. However, in blood no precipitating $\operatorname{IgG}$ antibodies against molds were found. Exogenic allergic alveolitis was suspected and the patient was started on oral steroids with an initial dose of $0.75 \mathrm{mg} / \mathrm{kg}$, which was rapidly reduced.

\section{First treatment: $1 / 2005$ to $4 / 2005$}

Our initial steroid dose was $0.75 \mathrm{mg} / \mathrm{kg}$ (=Aprednislon $50 \mathrm{mg}$ ) and she improved markedly. FEV1 and VC rose to 2.40 and 3.551 , respectively, however diffusion capacity went down to $79 \%$. The course of lung function parameters is reported in Fig. 1 and Table 1. The HR-CT done in February already indicated regression of opacities and steroid was slowly reduced to a quarter of the initial dose (Aprednislon $12.5 \mathrm{mg}$ ). The course of HR-CT scans is shown in Fig. 2. 


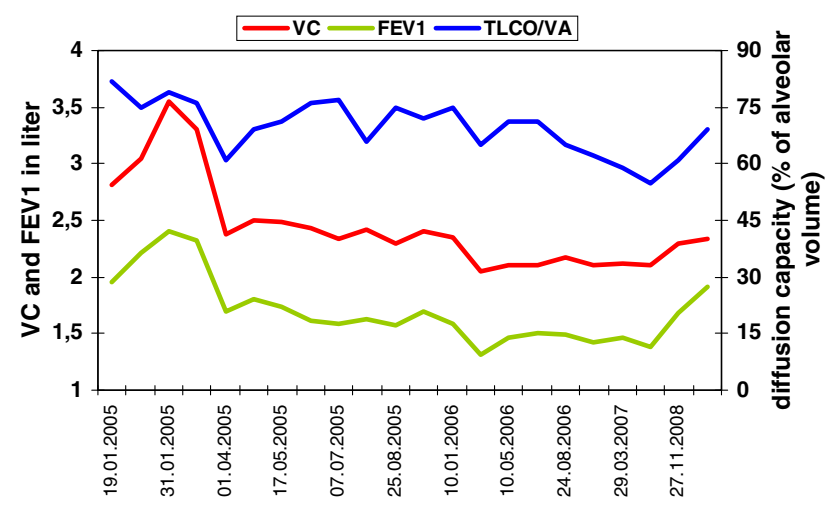

Fig. 1 Dynamic of lung function tests (vital capacity VC, FEV1, and diffusion capacity TLCO/VA) Date: from 1/05 until 4/09

In April 2005, the patient clinically deteriorated, computed tomography again showed patchy bilateral opacities and the lung function parameters went down to a FEV1 of $1.701, \mathrm{VC}$ of 2.381 , and a diffusion capacity of $61 \%$. To clarify the diagnosis an open lung biopsy was done in July
2005 [1-3]. Histology revealed centrilobular emphysema, activated alveolar cells, granulated polyps in the terminal bronchioli and alveolar ducts. Fibrin and foam cells were found in the alveoli. Diagnosis: cryptogenic organizing pneumonia [4].

\section{Second treatment: $5 / 2005$ to $4 / 2006$}

Steroid dosis was raised to $0.5 \mathrm{mg} / \mathrm{kg}$ (Aprednislon $37.5 \mathrm{mg}$ ) and the patient improved again. In August 2005, steroid treatment was reduced to $12.5 \mathrm{mg}$ due to massive weight gain, but azathioprine $150 \mathrm{mg}$ was added. In March 2006, steroid was reduced to $10 \mathrm{mg}$ and azathioprine to $100 \mathrm{mg}$. Two weeks later, the patient was admitted to hospital due to dyspnoea in the course of a cold. Although there was no sign of muscle weakness, an elevated creatine kinase $(\mathrm{CK})$ of $3000 \mathrm{U} / 1(-145 \mathrm{U} / \mathrm{l})$ was found. As we attributed the elevated $\mathrm{CK}$ value to massive cough, no diagnostic steps were taken. Weeks later the patient developed
Table 1 Lung function and blood gas analysis parameters

\begin{tabular}{lllll}
\hline & $1 / 05$ & Maximum & Minimum & $4 / 09$ \\
\hline Vital capacity in liter and \% pred & $2.82(72 \%)$ & $3.55(91 \%)$ & $2.05(53 \%)$ & $2.31(63 \%)$ \\
FEV1 in liter and \% pred & $1.96(61 \%)$ & $2.40(74 \%)$ & $1.31(41 \%)$ & $1.91(60 \%)$ \\
Diffusion capacity/alveolar volume & $82 \%$ & $82 \%$ & $55 \%$ & $69 \%$ \\
$\mathrm{pO}_{2}$ in mm Hg & 77 & 85 & 66 & 72 \\
$\mathrm{pCO}_{2}$ in mm Hg & 31 & 35 & 31 & 35 \\
\hline
\end{tabular}

Fig. 2 HR-CT scan at the start of treatment (a 1/05), first improvement (b 2/05), first relapse (c 4/05), and final CT (d 1/09) at stable state (no disease)
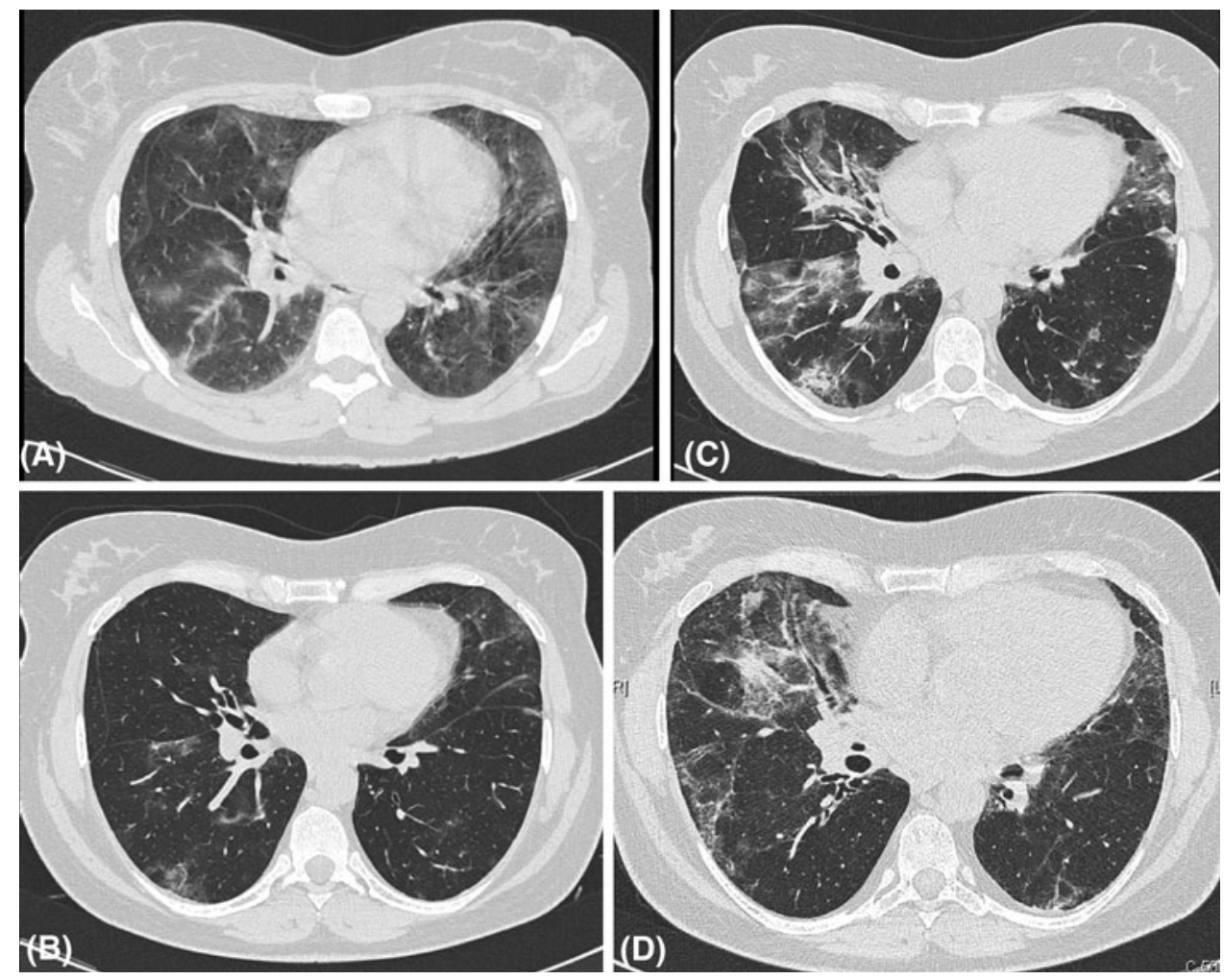
Fig. 3 MRT scan at the start of plasmaapheresis showing massive muscle edema (a 8/06; CK > $10.000 \mathrm{U} / \mathrm{l}$ ), improvement (b 10/07; CK 3500 U/l), and final MRT (c 12/08) at remission (CK in the normal range)
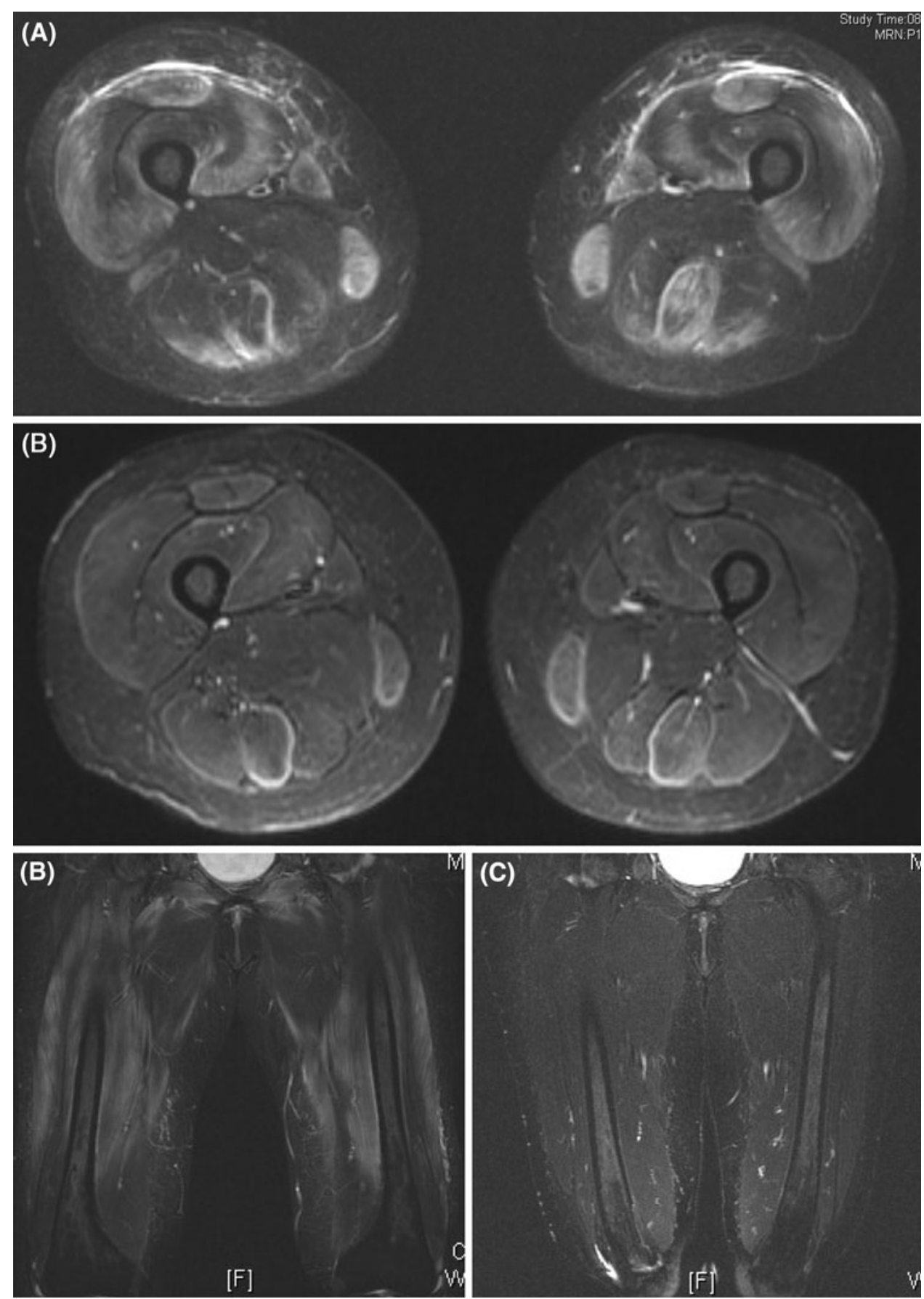

progressive weakness of her upper arms and legs with elevation deficit. She could barely get up from a chair. The neurologist suspected myositis.

Laborchemically, autoantibodies against the signal recognition particle (SRP, titer 1:5120) were found, which could be associated with myositis. Magnetic resonance tomography (MRT) showed muscle edema in several muscles of the pelvis and the upper legs corresponding to active myositis. The radiologic course of MRT is demonstrated in Fig. 3. An open muscle biopsy of the left sartorius muscle was done in May 2005. Histology revealed moderate, immunologically mediated myositis with necrosis of single muscle fibers with partial regeneration, mild inflammatory cell infiltrates, HLA class-1 upregulation, and deposition of complement complexes in the terminal capillars. Diagnosis: myositis, possibly driven by an anti-SRP autoimmune mechanism.

SRP positive myositis may be associated with difficulties in swallowing and can also affect the heart [5]. The echocardiogram of the heart showed regular ventricular motility and the pulmonary arterial pressure was not elevated. Oesophagal motility was regular. 


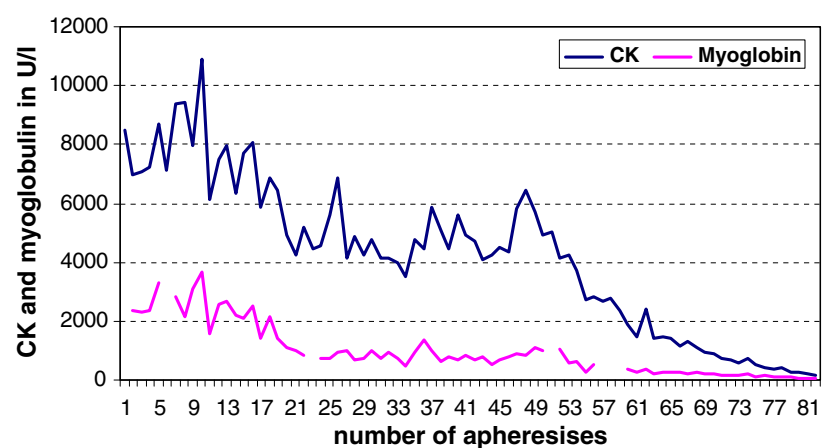

Fig. 4 Dynamics of creatinine kinase (CK) and myoglobin from the start of plasmaexchange in combination with immunoadsorption $(n=82)$. Date: from $7 / 06$ until $9 / 08$, since $9 / 08$, CK is in the normal range

\section{Third treatment: 5/2006 to $4 / 2009$}

Initial treatment consisted of a single dose of $1.000 \mathrm{mg}$ prednislone on five consecutive days and two courses of high dose intravenous immunoglobulin (IVIG) $30.000 \mathrm{mg}$ on five consecutive days $(2 \times 150.000 \mathrm{mg}$ total dose, i.e., $2,000 \mathrm{mg} / \mathrm{kg}$ body weight), as she refused further long term steroid treatment [6]. However, muscle weakness as well as fatigue increased despite therapy and creatine kinase rose to a total of $>10.000 \mathrm{U} / \mathrm{l}$. Finally, the patient was admitted to the general hospital of Vienna (AKH) for immunoadsorption. Treatment was started in August 2006 using Ig-Therasorb®columns three times a week. Immunoadsorption-procedure was performed as previously described [7, 8].

Due to unsatisfying treatment success, plasmaexchange (3L) was added to immunadsorption. Within weeks of treatment the patient felt considerably better and her muscle strength improved although creatine kinase was stable at about $10.000 \mathrm{U} / \mathrm{l}$. As myositis developed under steroid and azatioprine, we stopped azatioprine (8/2006), but kept the patient on $5 \mathrm{mg}$ Aprednislone for another 3 months (11/ 2006). The MRT, done in December 2006 already revealed a significant decrease of muscle edema. Her physical condition improved slowly and she started taking regular walks of increasing distance.

In 2007 and 2008 the patient further improved, plasmaexchange in combination with immunoadsorption was done in intervals of once every 2-3 weeks and creatine kinase went down step by step (Fig. 4). Her physical fitness was fairly good, the daily training program went on, fatigue decreased and lung function parameters were completely stable with a diffusion capacity of 59\%. Extracorporeal treatment was and still is tolerated excellently without a single side effect.

In $1 / 2009$, plasmaapheresis is still done every 3 weeks although creatine kinase is almost in the normal range
(157 U/l). The patient is completely stable and lung function even improved. The HR-CT of $1 / 2009$, as already in 10/2007, showed no sign of activity of COP but diffuse fibrosis especially in the middle lobe. Finally, the MRT of $11 / 2008$ was completely normal with no sign of muscle edema. In April 2009, anti SRP antibodies could no longer be detected in the blood.

\section{Discussion}

We report of a patient with cryptogen organizing pneumonia and SRP positive necrotising myositis without cardiac involvement and no sign of dysphagia. This case is unusual, as myositis showed full regression without oral immune suppression but with extracorporeal treatment, performed as a combined therapy of plasmaexchange and immunoadsorption, which is said to be of little to no use in treating myositis [5, 9-12]. However, plasmaapheresis is already done for almost 3 years and is still continued without any side effects. According to Hengstman et al. [9, 13], treatment for myositis may be done for years.

The signal recognition particle is a protein targeting system, acting as an adaptor between protein synthesis and the translocation machinery in the membrane. Its function is the co-translocation transport of secretory and membrane proteins. The SRP cycle is a GTP dependent process [14]. In myositis, anti-SRP autoantibodies are found in 5\% of cases.

Interstitial lung disease may be found in one quarter of patients suffering from anti-SRP autoimmune myositis, not differing in incidence from polymyositis or dermatomyositis $[5,9,11,16]$. In our patient, cryptogenic organizing pneumonia occurred about one and a half years prior to the emergence of myositis, although anti-SRP antibodies were present from the very beginning. Although, we can only speculate if SPR-autoantibodies have induced cryptogenic organizing pneumonia, literature reports interstitial lung disease in about one-third of cases preceeding autoimmune myositis [5, 9, 17]. According to Tazelaar [18], polymyositis or dermatomyositis may be accompanied by either usual interstitial pneumonia (UIP), diffuse alveolar damage (DAD) or bronchiolitis obliterans organizing pneumonia (BOOP, now called COP). Diffuse alveolar damage is reported to have the worst prognosis and bronchiolitis obliterans organizing pneumonia (BOOP/COP) has the most favorable prognosis $[10,15,19]$. Anti-SRP antibodies, which are mainly polymyositis specific, may also be found in dermatomyositis or systemic sclerosis [5, 9, 13]. In a recent report, Suzuki et al. [20] suggest to classify SRP positive myositis as a particular form of polymyositis.

SRP positive myositis occurs in adults peaking at about 50 years (5), but it may also be found in children, although 
very rarely $[20,21]$. The onset of myositis is often accompanied by a viral infection, as was probably the case in our patient. Interestingly, myositis occurred despite immune suppression. It is noteworthy that we reduced the dosis of steroid and azatioprine prior to the emergence of myositis.

The first line treatment for SRP positive myositis is steroid $(1 \mathrm{mg} / \mathrm{kg})$, as second line treatment azathioprine or methotrexate is recommended [5]. Intravenous immunogobulins (IVIG) may also suppress autoimmune disease by binding autoantibodies [6]. However, despite two courses of IVIG ( $2 \mathrm{~g} / \mathrm{kg} \mathrm{BW})$ worsening of myositis occurred. Data on plasmapheresis in SRP positive myositis are very rare. Hengstmann et al. [9] reported of two patients in their study, however the treatment outcome was not mentioned.

If SPR-autoantibodies have induced COP, then we are dealing with the more common secondary cryptogenic organizing pneumonia. The first relapse of COP was probably attributed to reducing steroids too quickly, after raising steroids the disease activity was slowly declining. To which extent extracorporeal treatment helped to cure organizing pneumonia will remain unanswered. Lung function parameters were at its worse as myositis emerged, however during the course of myositis the patient never mentioned an impairment of her respiratory muscles.

Although some questionmarks remain, this is a rather unique case of the rare SRP positive myositis showing complete remission to plasmaexchange combined with immunoadsorption without additional immune suppression. Although a case report is no evidence for the efficacy of a treatment, also plasmapheresis may be useful in patients suffering from SRP positive myositis.

Acknowledgments We want to thank Dr. Hilde Veterale and Prof. Gerhard Mostbeck from the Department of Radiology, Wilhelminenspital for their help.

\section{References}

1. British Thoracic Society Interstitial Lung Disease Guideline Group (2008) Interstitial lung disease guideline. Thorax 63(Suppl V):v1-v58

2. American Thoracic Society/European Respiratory Society (2002) International multidisciplinary consensus classification of the idiopathic interstitial pneumonias. Am J Respir Crit Care Med 165:277-304

3. Katzenstein AL, Mukhopadhyay S, Myers JL (2008) Diagnosis of usual interstitial pneumonia and distinction from other fibrosing interstitial lung diseases. Hum Pathol 39:1275-1294. doi:10.1016/ j.humpath.2008.05.009

4. Cordier JF, Costabel U, duBois R (2004) Cryptogenic organizing pneumonia. Orphanet encylcopedia, October 2004. http://www. orphanet/data/patho/GB/uk-CryptoOrgPneum.pdf

5. Kao AH, Lacomis D, Lucas M, Fertig N, Oddis CV (2004) Antisignal recognition particle autoantibody in patients with and patients without idiopathic inflammatory myopathy. Arthritis Rheum 50:209-215. doi:10.1002/art.11484

6. Nelson RP, Ballow M (2003) Immunomodulation and immunotherapy: drugs, cytokines, cytokine receptors and antibodies. J Allergy Clin Immunol 111:S720-S732. doi:10.1067/mai.2003.146

7. Dittrich E, Schmaldienst S, Langer M, Jansen M, Hörl WH, Derfler K (2002) Immunoadsorption and plasma exchange in pregnancy. Kidney Blood Press Res 25:232-239. doi:10.1159/ 000066343

8. Schmaldienst S, Müllner M, Goldammer A, Spitzauer S, Banyai S, Hörl WH, Derfler K (2001) Intravenous immunoglobulin application following immunoadsorption: benefit or risk in patients with autoimmune diseases? Rheumatology 40:513-521. doi:10.1093/ rheumatology/40.5.513

9. Hengstman GJ, ter Laak HJ, Vree Egberts WT, Lundberg IE, Moutsopoulos HM, Vencovsky J, Doria A, Mosca M, van Venrooij WJ, van Engelen BG (2006) Anti-signal recognition particle autoantibodies: marker of a necrotising myopathy. Ann Rheum Dis 65:1635-1638. doi:10.1136/ard.2006.052191

10. Knoell KA, Hook M, Grice P, Hendrix J (1999) Dermatomyositis associated with bronchiolitis obliterans organizing pneumonia. J Am Acad Dermatol 40:328-330. doi:10.1016/S0190-9622(99) 70478-0

11. Dalakas MC, Hohlfeld R (2003) Polymyositis and dermatomyositis. Lancet 362:971-982. doi:10.1016/S0140-6736(03)14368-1

12. Choi EHS, Isenberg DA (2002) Treatment of dermatomyositis and polymyositis. Rheumatology 41:7-13. doi:10.1093/rheumatology/ 41.1.7

13. Brouwer R, Hengstman GJ, Vree Egberts W, Ehrfeld H, Bozic B, Ghirardello A, Grøndal G, Hietarinta M, Isenberg D, Kalden JR, Lundberg I, Moutsopoulos H, Roux-Lombard P, Vencovsky J, Wikman A, Seelig HP, van Engelen BG, van Venrooij WJ (2001) Autoantibody profiles in sera of European patients with myositis. Ann Rheum Dis 60:116-123. doi:10.1136/ard.60.2.116

14. Wild K, Rosendal KR, Sinning I (2004) A structural step into the SRP cycle-microreview. Mol Microbiol 53:357-363. doi:10.1111/j.1365-2958.2004.04139.x

15. Kalenian M, Zweiman B (1997) Inflammatory myopathy, bronchiolitis obliterans/organizing pneumonia and anti-Jo-1 antibodiesan interesting association. Clin Diagn Lab Immunol 4:236-240

16. Imaski T, Tanaka S, Ogura T, Ishikawa A, Takahashi T (1996) Polymyositis and Sjögren's syndrome associated with bronchiolitis obliterans organizing pneumonia. Intern Med 35:231-235. doi:10.2169/internalmedicine.35.231

17. Fata F, Rathore R, Schiff C, Herzlich BC (1997) Bronchiolitis obliterans organizing pneumonia as the first manifestation of polymyositis. South Med J 90:227-230

18. Tazelaar HD, Viggiano RW, Pickersgill J, Colby TV (1990) Interstitial lung disease in polymyositis and dermatomyositis: clinical features and prognosis as correlated with histological findings. Am Rev Respir Dis 141:727-733

19. Lee CS, Chen TL, Tzen CY, Lin FJ, Peng MJ, Wu CL, Chen PJ (2002) Idiopathic inflammatory myopathy with diffuse alveolar damage. Clin Rheumatol 21:391-396. doi:10.1007/s100670 200104

20. Suzuki S, Satoh T, Sato S, Otomo M, Hirayama Y, Sato H, Kawai M, Ishihara T, Suzuki N, Kuwana M (2008) Clinical utility of antisignal recognition particle antibody in the differential diagnosis of myopathy. Rheumatology 47:1539-1542. doi:10.1093/rheumatology/ken 325

21. Rouster-Stevens KA, Pachman LM (2008) Autoantibody to signal recognition particle in African American girls with juvenile polymyositis. J Rheumatol 35:927-929 